\title{
Facets of Personality and the Phenomenology of Autobiographical Memory
}

\author{
DAVID C. RUBIN* and ILENE C. SIEGLER \\ Duke University, USA
}

\begin{abstract}
SUMMARY
The relationship between individual differences in autobiographical memory and personality was examined by having 118 undergraduates complete the NEO Personality Inventory after rating 15 word-cued autobiographical memories on 20 scales. The Openness to Feelings facet (O3) correlated with measures of belief in the accuracy of memories, recollection, sensory imagery and emotion. Four other facets had correlations with belief (A3-Altruism, E1 - Warmth, E4-Activity, E6Positive Emotions). These facets also deal with emotional components of personality. In multiple regressions, measures of belief and measures of recollection were predicted by different variables, and for measures of belief, the $\mathrm{O} 3$ facet increased the variance accounted for beyond that of just the cognitive variables. Our results are consistent with and extend studies of the effects of depression and emotional suppression on autobiographical memory. Copyright (C) 2004 John Wiley \& Sons, Ltd.
\end{abstract}

In clinical psychology, the contents of autobiographical memory are often used to infer and attempt to alter personality. Here we focus on the cognitive processes and phenomenological judgments involved in autobiographical memory rather than on the contents. Given the increase in interest in the effects of individual differences measures related to personality on autobiographical memory (Read \& Winograd, 1998), a study examining personality in a broad way would provide a needed base of comparison for more specific investigations. It would be of great practical importance to know if and how differences in personality traits were related to individual differences in memory. To begin such a project we need to commit to a theoretical view of personality and of autobiographical memory that allow both to be measured and interrelated. For personality we use the Five Factor Model (Digman, 1990; John \& Srivastava, 1999; McCrae \& Costa, 1999). We view autobiographical memory as an integration of component systems (Rubin, 1998; Rubin, Schrauf, \& Greenberg, 2003).

\section{INDIVIDUAL DIFFERENCES IN PERSONALITY}

The NEO Personality Inventory (Costa \& McCrae, 1992) provides a comprehensive assessment of adult personality with five domains and 30 facets, six facets within each

*Correspondence to: David C. Rubin, Department of Psychological and Brain Sciences, Duke University, Durham, NC 27708-0086, USA. E-mail: rubin@psych.duke.edu

Grant sponsor: National Heart Lung and Blood Institute; grant number: R01 HL55356 co-funded by the National Institute of Aging.

Grant sponsor: National Institute of Mental Health; grant number: R01 MH 066079.

Copyright (C) 2004 John Wiley \& Sons, Ltd. 
domain. The instrument embodies a conceptual model based on factor analytic research on the structure of personality. It was designed to reflect the traits, in natural language, that cover the full range of normal behaviours including thoughts and feelings. The 30 facets can be considered as personality traits, measured as self-descriptions, that individuals use to describe their emotional, interpersonal, experiential, attitudinal, and motivational styles. We concentrate on facets (rather than the domains) as they are of sufficient specificity that we expect them to be related to specific cognitive strategies and styles (Siegler \& Brummett, 2000).

The self description of personality requires that individuals make judgments about typical past actions or thoughts in order to agree or disagree with a series of 240 statements (eight for each of the 30 facets) such as 'I am not a worrier,' 'I rarely experience strong emotions,' and 'I tend to assume the best about people' (Costa \& McCrae, 1992). Thus, the personality description provided is based on personal semantic memory. Because of this, as well as examining the extent to which individual differences in personality are associated with individual differences autobiographical memory, this study can be seen as investigating how differences in the recall of typical, repeated actions and thoughts affects individual differences in the recall of specific events.

\section{A MODEL OF AUTOBIOGRAPHICAL MEMORY}

We view autobiographical memories (and memories in general, Rubin, 1995a) as the products of component processes, with each process occurring in a separate behaviourally and neurally defined system (Greenberg \& Rubin, 2003; Rubin, 1995b, 1998, 2002; Rubin, Feldman, \& Beckham, 2003; Rubin, Schrauf et al., 2003; Schrauf \& Rubin, 1998, 2000). These component processes are an integrative memory system, imagery in individual modalities, as well as multimodal spatial imagery, language, narrative reasoning, and emotions. There is considerable support for this multiple-systems model behaviourally and neuropsychologically (Greenberg \& Rubin, 2003; Rubin \& Greenberg, 1998), and the same multiple-systems model is needed to explain other complex cognitive tasks such as memory for oral traditions (Rubin, 1995a, 1995b). Under this model, belief and recollection are not separate subsystems. Rather they are meta-cognitive judgments that are based on the activity of other systems. Table 1 provides a list and description of our measures along with the names to which we refer throughout the text. The full questions are given in the Appendix. Each question is a proxy for one or more theoretical ideas. A discussion of the theoretical motivation for these variables can be found in Rubin, Schrauf et al. (2003).

We consider two phenomenological properties of autobiographical memories in detail, recollection and belief. Baddeley (1992), Greenberg and Rubin (2003), and Rubin (1998) identified recollection, or the reliving of the original experience as the defining feature of autobiographical memory. Brewer (1996) noted that psychologists and philosophers often use recollection to distinguish autobiographical memory from other forms of memory. Similarly, Tulving $(1983,1985$; Wheeler, Stuss, \& Tulving, 1997) claims that the retrieval of an episodic memory requires the rememberer to be presently conscious of a prior conscious experience. Thus, understanding what leads to recollection is important theoretically because it is a defining feature of autobiographical memory. Understanding what leads to recollection is important practically because it is used to distinguish autobiographical memory from other states, such as imagining or dreaming, and from the retrieval of facts about the self. Belief is also a basic feature of autobiographical 
Table 1. Autobiographical memory variables used in study

\begin{tabular}{ll}
\hline Variable & Brief description of the rating scale \\
\hline $\begin{array}{l}\text { Recollection and belief } \\
\text { Recollection }\end{array}$ & Average of reliving and back in time \\
Reliving & I am reliving the original event \\
Back in time & I travel back to the time when it happened \\
Remember/know & I remember it rather than just knowing it happened \\
Belief & Average of real/imagine, accurate, testify, and (8一 - persuade) \\
Real/imagine & I believe the event in my memory really occurred \\
Accurate & Distorted vs. accurate as a neutral observer \\
Testify & Would you be confident enough to testify in court \\
Persuade & I could be persuaded that my memory was wrong \\
Component processes & \\
See & I can see it in my mind \\
Setting & I can recall the setting where it occurred \\
Spatial & I know the spatial layout \\
Hear & I can hear it in my mind \\
Talk & I or other people are talking \\
In words & It comes to me in words \\
Story & It comes to me as a coherent story \\
Emotions & I can feel now the emotions that I felt then \\
Reported properties of events or memories & It is significant for my life \\
Importance & I have thought or talked about this event \\
Rehearsal & It occurred once at one particular time \\
Once/many & A merging of events versus an extended event \\
Merged/extended & Please date the memory (month/day/year) \\
Age of memory & \\
\hline &
\end{tabular}

memories (Brewer, 1996). Philosophers have noted that memory is a source of belief, it provides justification for belief in much the way that perception does. Belief in the accuracy of memory affects whether people will act or testify on their memories. Thus, knowing what causes memories to be believed is of great practical importance.

In contrast, to the cognitive meta-judgments of recollection and belief, we view imagery, language, narrative and emotion as component processes. The most important of these in the psychological and philosophical literatures is visual imagery (see Brewer, 1996; Greenberg \& Rubin, 2003; Larsen, 1998; Rubin, 1998; Rubin, Burt, \& Fifield, 2003; and Greenberg \& Rubin, 2003 for reviews). Visual imagery can be divided on behavioural and neural grounds into two systems: object or descriptive imagery and spatial imagery. More colloquially, these comprise a 'what' system (measured by our see variable) and a 'where' system (measured by our setting and spatial variables) (Farah, Hammond, Levine, \& Calvanio, 1988; Rubin, 1995a). Other sensory modalities, language, narrative, and emotions each have their own organizations and ways of processing information and thus contribute in unique ways to having an autobiographical memory, and we therefore measure the contributions independently.

Cognitive psychologists typically take one measure of a concept such as recollection and assume it is the best one. Thus, Tulving's $(1983,1985)$ remember/know judgment is the standard for laboratory recollection. In contrast, because of the complexity and lack of prior experimental work on the phenomenological properties, we consider three questions that could measure aspects of recollection and four that could measure aspects of belief. 
Our questions tap different aspects of recollection and belief, so we do not expect them to be identical. For instance, whether one would testify in court on the basis of a memory and whether one felt they recalled an event as a neutral observer would each tap different aspects of belief in the accuracy of a memory. In our prior research (Rubin, Schrauf et al., 2003), remember/know judgments correlated more highly with measures of belief than measures of recollection and were predicted in multiple regression equations in ways that were more similar to measures of belief. We therefore do not group remember/know judgments with measures of recollection. A replication of our earlier finding will more firmly call into question the use of remember/know judgments as measures of recollection in autobiographical memory. Also in our prior research (Rubin, Schrauf et al., 2003), we found that setting was a better predictor of belief and that see was a better predictor of recollection, consistent with the view that contextual rather than perceptual information is a better predictor of belief (Johnson, Foley, Suengas, \& Raye, 1988).

\section{STRATEGY AND PREDICTIONS}

If there is any relation between personality and autobiographical memory as measured here, it is almost certainly that the relation would be reciprocal; individual differences in cognitive processes would lead to individual differences in personality and vice versa. Individual differences in both would affect the retrieval of individual autobiographical memories. However because personality traits, but not necessarily the differences in cognitive style measured here, are assumed to be enduring characteristics, we find it more natural to consider the effects of personality on the memories recalled in our experiment rather than the effects of memory on personality. Longitudinal studies are needed to untangle the relationship.

Given the assessment of personality afforded by the NEO and the properties of autobiographical memory commonly measured in cognitive psychology, we can offer a comprehensive first step in the description of how personality traits and properties of memory interact. But there are also data and theory to support specific hypotheses. In our earlier work (Rubin, Schrauf et al., 2003), we found that in individual differences analyses, we could predict measures of recollection (as measured by relive and back in time) much better than measures of belief (as measured by real/imagine) with the other component processes and properties of memories listed in Table 1 ( $r$-squares of $\sim 0.6$ versus $\sim 0.2$ ). This led us to suspect that belief would be predicted by non-cognitive factors. We found that a measure of dissociation (the Dissociative Experiences Scale, DES, Bernstein \& Putnam, 1986; Carlson \& Putnam, 1993) correlated -0.30 with our real/imagine measure, but not significantly with our measures of recollection. Similarly, a measure of depression (the Beck Depression Inventory, BDI, Beck, Ward, Mendelson, Mock, \& Erbaugh, 1961) correlated -0.33 with real/imagine, but not significantly with our measures of recollection. In multiple regressions, the DES and the BDI entered significantly into multiple regression of real/imagine, adding 0.13 and 0.06 to the $r$-squared beyond what just the cognitive variables could do. The DES also correlated positively with memories being judged as more important and with the amount of auditory imagery in the memories, the latter correlation perhaps caused by questions concerning auditory imagery being present in the DES itself. In contrast, the BDI correlated negatively with visual and auditory imagery and most strongly with decreased narrative coherence. From these findings we expect that the NEO facets, which were devised to be personality rather than cognitive 
measures, will predict our measures of belief better than our measures of recollection, and also that the NEO facets that measure positive affect should produce correlations similar to the BDI, but with opposite signs.

Based on their laboratory studies of emotional suppression, Richards and Gross (2000) predicted and found that the more highly subjects rated themselves on the suppression of emotions, the lower they rated how well they remembered their memories for conversations and the poorer they recalled of emotion-regulation episodes that they had recorded in a diary. To ensure that the effects were specific to emotional suppression, they also predicted and found that measures of neuroticism and social desirability did not affect memory ratings or ability. The opposite of the suppression of emotions in the NEO is the O3 facet, Openness to Feelings, which has questions asking subjects to endorse statements including phrases such as: I 'experience strong emotions,' 'pay attention to my feelings,' 'experience a wide range of emotions,' and 'notice the moods or feelings that different environments produce.' Thus the $\mathrm{O} 3$ facet is about the range of emotions experienced and their intensity rather than their valence. From Richards and Gross (2000), we therefore expect that the $\mathrm{O} 3$ facet will act opposite to measures of emotional suppression and that the Neuroticism factor, and its six facets, will not show any effects on autobiographical memory.

Richards and Gross (2000) came to their predictions from a specific question and theory about emotional suppression. Our goal is more general. By asking the general question of which properties of autobiographical memory are affected by which facets of personality, in addition to testing specific hypotheses, we provide a broader description that can constrain theory at a more general level. If we find that the $\mathrm{O} 3$ facet predicts increased recollection and belief in autobiographical memories then we can look at the personality trait of Openness to Feelings as a cognitive style that increases aspects of autobiographical memory. If the $\mathrm{O} 3$ facet also correlates with some of the component processes we measure, then we should be able to form hypotheses on the mechanisms for its operation. If we find that, in addition to the Neuroticism facets, most other facets have little effect on memory, then we will add to the divergent validity that Richards and Gross found. But there is also the potential to discover if other facets affect autobiographical memory.

\section{METHOD}

\section{Subjects}

One hundred and eighteen Duke University undergraduates participated. Their mean age was $19.01(S D=1.03)$; 72 were female.

\section{Materials}

Each subject was presented with a version of the autobiographical memory questionnaire (AMQ). It consisted of a booklet with a cover page with instructions, a double-sided sample page containing the cue word tree and 19 questions about the memory it cued, a dividing page, and then 15 more double-sided pages, each of which contained one of 15 cue words from Rubin, Schrauf et al. (2003) and the 19 questions referring to the memory it elicited. The questions are listed in the Appendix; as noted there, question 18 was transformed into two measures here: once/many and merged/extended. In addition, we calculated an overall measure of recollection equal to the average of relive and back in 
time and an overall measure of belief equal to (real/imagine + accurate + testify $+(8-$ persuade))/4. The NEO Personality Inventory, Revisited booklet was given with a machine readable answer form and the raw data converted to $T$-scores using norms for the appropriate age and gender of the subjects.

\section{Procedure}

The subjects were tested in groups. They were read the printed instructions and asked to think of a memory to the word tree and then answer all 19 questions about it. Each of the 19 questions was discussed briefly and any questions from the subjects were answered. The subjects were then asked to recall a memory to each of the remaining 15 cue words in turn and, while they were thinking about that memory, to answer the 19 questions about it. Ratings given while an activity is ongoing, in contrast to retrospective reports, reflect the cognitive processes of that activity in ways that produce lawful relations and relate in reasonable ways to objective measures (Ericsson \& Simon, 1993) and so we obtained our ratings while our subjects were being asked to remember each autobiographical memory. The NEO followed the AMQ.

\section{RESULTS AND DISCUSSION}

\section{Means and correlations}

The means and standard deviations for all autobiographical memory variables are shown in Table 2. Because the direction of the persuade scale is opposite to other belief variables, it was reverse scored; that is 8 - the value given was used as the score for persuade. There

Table 2. Means and standard deviations of autobiographical memory variables

\begin{tabular}{lcc}
\hline Variable & Mean & SD \\
\hline Recollection & 4.85 & 0.86 \\
$\quad$ Reliving & 4.75 & 0.91 \\
Back in time & 4.95 & 0.92 \\
Remember/know & 5.78 & 0.76 \\
Belief & 5.32 & 0.71 \\
$\quad$ Real/imagine & 5.77 & 0.74 \\
Accurate & 5.33 & 0.80 \\
Testify & 5.17 & 0.85 \\
Persuade & 5.00 & 0.77 \\
See & 5.61 & 0.63 \\
Setting & 5.96 & 0.62 \\
Spatial & 5.12 & 0.92 \\
Hear & 4.23 & 1.04 \\
Talk & 4.23 & 1.00 \\
In words & 3.36 & 1.61 \\
Story & 4.68 & 0.96 \\
Emotions & 4.74 & 0.92 \\
Importance & 3.44 & 0.82 \\
Rehearsal & 3.42 & 0.75 \\
Once/many & 0.71 & 0.17 \\
Merged/extended & 0.35 & 0.30 \\
Age of memory & 1553 & 893 \\
\hline
\end{tabular}


Table 3. Correlations of memory and NEO scales

\begin{tabular}{|c|c|c|c|c|c|c|c|c|c|c|c|}
\hline \multirow[t]{2}{*}{ AMQ variables } & \multicolumn{6}{|c|}{ NEO domains } & \multicolumn{5}{|c|}{ NEO facets } \\
\hline & $\alpha$ & A & $\mathrm{C}$ & $\mathrm{E}$ & $\mathrm{N}$ & $\mathrm{O}$ & A3 & E1 & E4 & E6 & $\mathrm{O} 3$ \\
\hline Recollection & 0.85 & 0.22 & 0.11 & 0.14 & 0.03 & 0.23 & 0.25 & 0.17 & 0.16 & 0.27 & 0.32 \\
\hline Reliving & 0.85 & 0.23 & 0.15 & 0.09 & 0.06 & 0.20 & 0.24 & 0.15 & 0.13 & 0.21 & 0.31 \\
\hline Back in time & 0.84 & 0.19 & 0.07 & 0.18 & -0.01 & 0.22 & 0.23 & 0.17 & 0.17 & 0.29 & 0.30 \\
\hline Remember/know & 0.83 & 0.15 & 0.07 & 0.19 & 0.00 & 0.36 & 0.26 & 0.23 & 0.23 & 0.26 & 0.36 \\
\hline Belief & 0.85 & 0.17 & 0.17 & 0.25 & -0.01 & 0.06 & 0.29 & 0.24 & 0.32 & 0.27 & 0.35 \\
\hline Real/imagine & 0.87 & 0.18 & 0.10 & 0.31 & -0.01 & 0.30 & 0.31 & 0.30 & 0.33 & 0.31 & 0.34 \\
\hline Accurate & 0.86 & 0.17 & 0.17 & 0.24 & 0.01 & 0.24 & 0.27 & 0.25 & 0.29 & 0.27 & 0.33 \\
\hline Testify & 0.81 & 0.09 & 0.15 & 0.24 & -0.06 & 0.34 & 0.19 & 0.15 & 0.27 & 0.25 & 0.32 \\
\hline Persuade & 0.79 & 0.16 & 0.20 & 0.13 & 0.02 & 0.14 & 0.27 & 0.16 & 0.24 & 0.14 & 0.27 \\
\hline See & 0.78 & 0.18 & 0.18 & 0.23 & 0.07 & 0.32 & 0.26 & 0.28 & 0.28 & 0.23 & 0.40 \\
\hline Setting & 0.79 & 0.12 & 0.28 & 0.24 & -0.06 & 0.22 & 0.29 & 0.24 & 0.31 & 0.23 & 0.27 \\
\hline Spatial & 0.87 & 0.06 & 0.03 & 0.21 & -0.15 & 0.30 & 0.18 & 0.10 & 0.27 & 0.29 & 0.22 \\
\hline Hear & 0.84 & 0.18 & 0.07 & 0.22 & 0.05 & 0.16 & 0.28 & 0.31 & 0.19 & 0.21 & 0.31 \\
\hline Talk & 0.82 & 0.18 & 0.11 & 0.28 & 0.01 & 0.20 & 0.29 & 0.30 & 0.22 & 0.25 & 0.29 \\
\hline In words & 0.96 & 0.04 & 0.09 & 0.08 & 0.10 & -0.05 & 0.20 & 0.14 & 0.10 & 0.10 & 0.09 \\
\hline Story & 0.80 & 0.21 & 0.06 & 0.28 & -0.05 & 0.23 & 0.31 & 0.26 & 0.23 & 0.32 & 0.28 \\
\hline Emotions & 0.81 & 0.16 & 0.10 & 0.19 & 0.07 & 0.24 & 0.15 & 0.21 & 0.22 & 0.23 & 0.35 \\
\hline Importance & 0.67 & -0.03 & -0.05 & -0.04 & 0.19 & 0.09 & 0.02 & 0.06 & -0.06 & -0.06 & 0.23 \\
\hline Rehearse & 0.71 & -0.04 & 0.05 & 0.19 & 0.12 & 0.05 & 0.08 & 0.13 & 0.15 & 0.15 & 0.18 \\
\hline Once/many & 0.57 & -0.02 & 0.00 & 0.13 & -0.15 & 0.21 & 0.06 & 0.04 & 0.14 & 0.09 & 0.15 \\
\hline Merged/extended & 0.78 & -0.09 & -0.03 & -0.04 & 0.09 & -0.04 & -0.10 & -0.07 & -0.06 & 0.03 & 0.01 \\
\hline Age of memory & 0.77 & -0.10 & -0.12 & -0.21 & 0.06 & 0.04 & -0.03 & -0.12 & -0.21 & -0.11 & 0.04 \\
\hline
\end{tabular}

Note: Values in bold are significant at $p<0.001$ level. No other correlations on any other facet are significant at $p<0.001$ level.

is substantial variability and range, allowing for individual differences analyses. Table 3 presents the reliabilities, which are good to excellent, for all the AMQ variables and the correlations between them and the NEO domains and the five (of a possible 30) NEO facets that had at least one correlation significant at the 0.001 level. As there were 118 subjects, being significant at the 0.001 level corresponded to accounting for approximately $10 \%$ of the variance. As there are 22 variables derived from the AMQ and five NEO domains factors and 30 NEO facets, there are 770 correlations. At the 0.05 level $(r=0.18)$, 39 would be significant by chance under the conservative (and false) assumption that the scales were all independent. At the 0.001 level $(r=0.30)$, less than one would be. Each NEO facet shown in Table 3 has at least two significant correlations at the 0.001 level not including the two AMQ variables (belief and recollection) that were based on sums of scales, thus adding to our confidence that the facets shown were not selected by chance.

First we examine Table 3 in terms of the AMQ variables, following the three conceptual divisions of Table 1: 'recollection and belief', 'component processes', and 'reported properties of events or memories'. None of the correlations that are significant at the 0.001 level are in the reported-properties-of-events-or-memories division. This makes interpretation of the results easier as factors such as the age of the memories or their importance can be ignored as the underlying causes of correlations of NEO facets with sensory imagery, recollection, and belief. Of the correlations with recollection and belief, only the $\mathrm{O} 3$ facet had significant correlations with measures of recollection; the $\mathrm{O} 3$ and other facets listed had correlations with a measure of belief and at least one of the component 
processes. Put another way, no facet had a high correlation with a component process that did not also have one with belief and vice versa.

Next we examine Table 3 in terms of the five NEO domains as a broad picture of personality. Two of the five domains had a significant correlation at the 0.001 level, Extroversion and Openness. This does not seem to be a random variation cut by an arbitrary $p$ level. The largest correlation on the Neuroticism domain is 0.19 and on the Agreeableness domain it is 0.23 . For the Conscientiousness domain, it is 0.20 with the exception of a 0.28 correlation with setting. Thus, two domains, $\mathrm{E}$ and $\mathrm{O}$, have at least eight correlations with the AMQ variables that are $0.23(p=0.01)$ or above with at least one correlation above 0.30 ( $p=0.001)$; whereas three domains, A, C, and $\mathrm{N}$, have one or none that are significant at the 0.01 level. As with having classes of AMQ variables that did not have large correlations, having NEO domains that are not involved in autobiographical memory simplifies interpretation. Again the results are surprisingly systematic.

We concentrate on the NEO facets rather than the domains because they are more specific and thus easier to interpret in terms of behavioural tendencies that might affect memory and cognition. In contrast, the domains provide broader general tendencies. Five of the 30 NEO facets have significant correlations at the 0.001 level: A3, E1, E4, E6, and O3, so the effects are quite specific. A3, which is part of the Agreeableness domain, is Altruism and asks subjects to endorse statements including phrases such as 'courteous,' 'thoughtful and considerate,' and 'charitable.' E1, which is part of the Extroversion domain, is Warmth and its items include 'warm and friendly person,' and 'outgoing' as well as some directly involving talk such as 'pleasure from chatting' and 'really enjoy talking to people.' Thus its correlations with the hear and talk variables are reasonable; people who spend more time in conversation and who find it more enjoyable should have more conversation as part of their autobiographical memories. E4 is Activity and its items include 'bursting with energy' and 'very active.' E6 is Positive Emotions and its items include 'jumped for joy,' 'ecstasy,' 'laugh easily.' Scoring highly on E6 is inconsistent with being depressed and it correlates most highly with real/imagine and story, two of the variables that the BDI correlated most negatively with in our earlier work (Rubin, Schrauf et al., 2003). O3 is correlated with the greatest number of AMQ variables and had the highest correlations. It correlated with all nine measures of belief and recollection except persuade and also with see, hear, and emotions. These correlations are in general consistent with earlier work by Richards and Gross (2000) and Rubin, Schrauf et al. (2003). The correlation with emotions is reasonable given that the scale measures openness to feelings. The correlations with the sensory variables of see and hear suggest that the effect on belief and recollection may be mediated by an increase in awareness of the sensory components of the memories as well as their emotional content.

Although the five facets that had significant correlations with the AMQ variables are from three different domains, they all are related to either an openness to express and experience emotions (O3) or a positive emotional state and outlook, in that, A3 is Altruism, E1 is Warmth, E6 is Positive Emotions, and E4 is Activity, which includes items inconsistent with being sad. In previous work with the facets of the NEO, Siegler and Brummett (2000) found that all of these facets correlated significantly with a well-being factor labelled 'positive relations with others.' This was a weighted summary of the appraisal sub-scale of the ISEL (Interpersonal Social Evaluation List, Cohen, Mermelstein, Kamarck \& Hoberman, 1985). This scale reflects a judgment that the individual has others who can be trusted, will provide advice on a variety of problems and act as a confidant, and an item indicating achievement of more than expected in personal 
relationships from college to mid-life (Siegler et al., 2003). Thus, it seems that having a generally positive attitude increases the belief in and, to a lesser extent, the recollection of autobiographical memories. This is consistent with our earlier work showing a decrease in belief with increases in BDI scores (Rubin, Schrauf et al., 2003). It is also consistent with work by Williams and colleagues (see Williams, 1996 for a review) that shows that with depression, memories become more vague and less specific. It is somewhat puzzling that here, and in our earlier work, once/many and merged/extended, which are based directly on Williams' work did not show significant effects, but we used a self rating of whether the events occurred once or were repeated whereas Williams used ratings by judges. What appears specific to a judge may be rated by the individual to whom it occurred as being based on multiple occurrences. If this is the case, it may be the ability to retrieve details of one of those instances that is crucial.

In addition to investigating how the NEO and AMQ variables correlated, we did an exploratory analysis to see if levels of responding on the NEO facets and domains affected the correlations among the cognitive variables. That is, did a particular personality trait affect the correlation among cognitive processes rather than just the reported mean level of those processes. Because we had 15 memories from each person we could examine the correlations among our 19 measures within each individual (excluding merged/extended, which has values only for those memories reported to span more than a day), producing for each individual $171(19 * 18 / 2)$ correlations. We could then ask, in an exploratory fashion, how these correlations were affected by mean levels on the NEO. To do this we correlated each of the 35 NEO variables (five domains and 30 facets) with a Fisher's z-score of each of the 171 correlations among the AMQ variables, producing 5985 correlations. Given the large number of correlations we again set the chance level at 0.001 ( 0.30 with 118 observations), which should have produced six significant correlations by chance if all our measures were random and independent. There were no significant correlations, suggesting that the NEO facets and domains affect mean levels of the AMQ variables, but not the relations among them.

If one excludes the merged/extended variable and recollection and belief, which are sums of other variables, there are 19 AMQ variables; there are five NEO facets that have significant correlations with them as shown in Table 3 . There are 276 correlations among these 24 variables. A standard way to provide a graphic approximation of such a large amount of information is to use a principal components analysis (PCA), as is done in Figure 1. PCA is much simpler than factor analysis in that the only option is the choice of the number of factors to display. Because there are 24 variables, there are 24 factors in the full analysis; the first two of which are shown in Figure 1 to provide a visual presentation of which variables are more closely related to each other, and the third factor is mentioned in the text. Here, unlike Table 4, the correlations among all variables are considered, none are excluded, there is no reduction in the strength of a correlation among variables caused by variance accounted for by another variable, and there is no division into independent and dependent variables. The factors axes are orthogonal linear combinations of the 24 variables that retain as much of the relationships of the full correlation tables as possible. The first six eigenvalues are greater than 1 . They are 8.76, 2.54, 1.93, 1.33, 1.22, and 1.02, and they account for $36,11,8,6,5$, and $4 \%$ of the total variance.

The once/many variable, which correlates minimally with the other variables, has coordinates that fall below the values shown on the figures (Factor $1=0.15$, Factor $2=-0.46$;) as does the age of memory variable, which correlates moderately, but uniformly with the other variables (Factor $1=-0.22$, Factor $2=0.02$ ). On the third Factor, all 


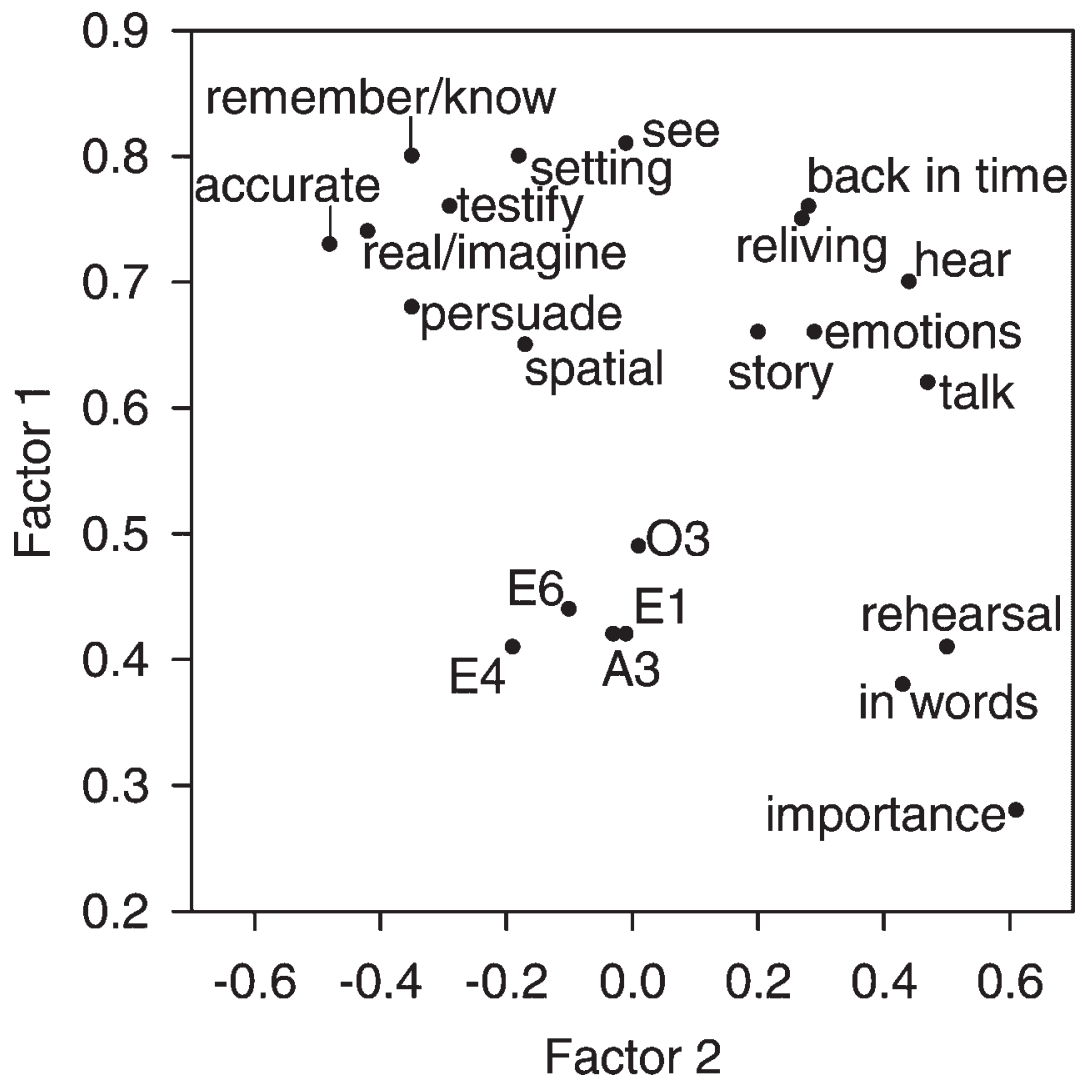

Figure 1. PCA of AMQ variables and NEO facets from Table 3

the AMQ variables have values between -0.22 and 0.17. A3, E1, E4, and E6 have values between 0.46 and 0.75 , but $\mathrm{O} 3$ is closer to the AMQ variables with a value of 0.21 , consistent with its higher correlations with many of the AMQ variables. If a threedimensional representation could be given instead of the two-dimensional Figure 1, the AMQ variables would be slightly below to slightly above the plane of Figure 1 and the NEO variables would be well above it, except for O3, which would be closer to the AMQ variables. Figure 1 shows the clustering of the NEO variables, the recollection variables and the belief variables. The differences seen in which variables predict belief and recollection in Table 4 are preserved here with setting, spatial and remember/know being closer to the belief variables than the recollection variables.

\section{Multiple regression analyses predicting belief and recollection}

We used multiple regression analyses to predict our measures of recollection and belief with 12 of the remaining 13 variables using the same between-subjects measures used throughout the paper. Merged/extended was excluded because it had missing values on the memories that were rated as occurring once. All combinations of the independent variables were tried and the equation with the highest $r$-squared that had only variables with beta weights significantly different from chance at the 0.05 level was chosen. Table 4 presents these results, labelling the 'type of analysis' as 'b/t' for between subjects. We then 
Table 4. Multiple regressions

\begin{tabular}{|c|c|c|c|c|c|c|c|c|c|c|c|c|c|}
\hline \multirow{2}{*}{$\begin{array}{l}\text { Dependent } \\
\text { variable }\end{array}$} & \multirow{2}{*}{$\begin{array}{l}\text { Type of } \\
\text { analysis }\end{array}$} & \multicolumn{11}{|c|}{ Beta weights for independent variable } & \multirow[t]{2}{*}{$R^{2}$} \\
\hline & & see & setting & spatial & hear & $\begin{array}{c}\text { in- } \\
\text { words }\end{array}$ & story & emotions & $\begin{array}{l}\text { once/ } \\
\text { many }\end{array}$ & age & E1 & $\mathrm{O} 3$ & \\
\hline \multirow[t]{3}{*}{ Recollection } & w/i & 0.22 & & & 0.22 & & 0.24 & 0.29 & & & & & 0.74 \\
\hline & $\mathrm{b} / \mathrm{t}$ & 0.34 & & & 0.24 & & 0.24 & 0.28 & & & & & 0.72 \\
\hline & $\mathrm{b} / \mathrm{t} \mathrm{NEO}$ & 0.34 & & & 0.26 & & 0.26 & 0.28 & & & -0.13 & & 0.74 \\
\hline \multirow[t]{3}{*}{ Reliving } & $w / i$ & 0.26 & & & 0.26 & & 0.12 & 0.25 & & & & & 0.68 \\
\hline & $\mathrm{b} / \mathrm{t}$ & 0.33 & & & 0.25 & & 0.13 & 0.33 & & & & & 0.70 \\
\hline & $\mathrm{b} / \mathrm{t} \mathrm{NEO}$ & 0.35 & & & 0.28 & & 0.15 & 0.33 & & & -0.14 & & 0.72 \\
\hline \multirow{5}{*}{$\begin{array}{l}\text { Back in } \\
\text { time } \\
\text { Remember/ } \\
\text { know }\end{array}$} & $\mathrm{w} / \mathrm{i}$ & 0.14 & 0.11 & & & & 0.31 & 0.28 & & & & & 0.64 \\
\hline & $\mathrm{b} / \mathrm{t}$ & 0.28 & & & 0.19 & & 0.32 & 0.20 & & & & & 0.59 \\
\hline & $\mathrm{w} / \mathrm{i}$ & 0.25 & & & & 0.16 & & 0.14 & & -0.23 & & & 0.61 \\
\hline & $\mathrm{b} / \mathrm{t}$ & & 0.66 & & & 0.14 & & & 0.18 & & & & 0.55 \\
\hline & $\mathrm{b} / \mathrm{t}$ NEO & & 0.63 & & & 0.13 & & & 0.16 & & & 0.16 & 0.57 \\
\hline \multirow[t]{3}{*}{ Belief } & $\mathrm{w} / \mathrm{i}$ & 0.24 & 0.19 & & & & 0.32 & & & -0.25 & & & 0.72 \\
\hline & $\mathrm{b} / \mathrm{t}$ & & 0.57 & & & & 0.18 & & & & & & 0.45 \\
\hline & $\mathrm{b} / \mathrm{t}$ NEO & & 0.58 & & & & & & & -0.15 & & 0.20 & 0.48 \\
\hline \multirow{3}{*}{$\begin{array}{l}\text { Real/ } \\
\text { imagine }\end{array}$} & $\mathrm{w} / \mathrm{i}$ & & 0.21 & & & & 0.27 & & & -0.19 & & & 0.52 \\
\hline & $\mathrm{b} / \mathrm{t}$ & & 0.60 & & & & & & & & & & 0.36 \\
\hline & $\mathrm{b} / \mathrm{t} \mathrm{NEO}$ & & 0.53 & & & & & & & -0.15 & & 0.20 & 0.41 \\
\hline \multirow[t]{3}{*}{ Accurate } & w/i & 0.25 & 0.24 & & & & & & & -0.21 & & & 0.49 \\
\hline & $\mathrm{b} / \mathrm{t}$ & & 0.58 & & & & & & & & & & 0.34 \\
\hline & $\mathrm{b} / \mathrm{t}$ NEO & & 0.53 & & & & & & & & & 0.19 & 0.37 \\
\hline \multirow[t]{2}{*}{ Testify } & w/i & & & 0.22 & & & 0.31 & 0.16 & & -0.22 & & & 0.69 \\
\hline & $\mathrm{b} / \mathrm{t}$ & & 0.45 & & & & 0.28 & & & -0.14 & & & 0.43 \\
\hline \multirow[t]{2}{*}{ Persuade } & $\mathrm{w} / \mathrm{i}$ & 0.19 & & & & & 0.29 & 0.17 & & -0.21 & & & 0.64 \\
\hline & $\mathrm{b} / \mathrm{t}$ & & 0.56 & & & & & & & & & & 0.32 \\
\hline
\end{tabular}

Note: $\mathrm{b} / \mathrm{t}$ is for the between subject analysis, $\mathrm{b} / \mathrm{t}$ NEO is for analyses in which a NEO scale had predictive value, and w/i for the within subject analysis. Persuade was reverse scored.

repeated the analysis including all NEO facets that were listed in Table 3. Where a NEO facet enters into an equation, there is a line labelled 'b/t NEO.' O3 enters into four equations related to belief, adding about 0.03 to the r-squared. E1 enters as a suppressor variable into reliving and recollection, and thus has no simple interpretation. It adds an additional 0.02 to the $r$-squared. As the beta weights for hear and story, two variables with which E1 correlates, increase when E1 enters, it may be correcting for some aspects of these variables. As it enters at the 0.05 level only for reliving and for recollection, and as recollection is the sum of reliving and another variable, back in time, it may also be a chance occurrence.

We also calculated multiple regressions within individual subjects, which are labelled as 'w/i' in Table 4. These regressions were done over the 15 memories for each subject separately, and the parameters of the resulting equations were averaged (see Estes, 1956, for a discussion of averaging such linear equations). A $t$-test was performed on the set of 118 beta weights associated with each independent variable to see if its mean was different from zero. This procedure was first done with all 12 independent variables. Next, the independent variable with the smallest average beta weight was removed if it was not statistically different from zero. This step was repeated until all remaining beta weights were statistically significant. We used the 0.0001 level instead of the 0.05 level to arrive at a roughly equal number of predictors in the between- and within-subjects equations in order to facilitate comparisons between them. The change in $p$ level from 0.05 between subjects to 0.0001 within subjects indicates the high degree of similarity among the 
regression equations of the individual subjects. In contrast to the more standard regression analyses done on the mean values of each subject for each variable, these within-subject analyses provide a view of the processes working within each individual.

The regression analyses, which are shown in Table 4, using the between and within units of analysis answer questions at different levels. The between subject analyses are at the standard individual differences level of analysis used throughout the paper. They are concerned with how the average rating of each subject on each measure interrelate. The within subject analyses are concerned with processes within each individual. The within subject correlations would not change if the mean value of each subject was subtracted from each variable and it is only these mean values that are used in the between subjects analyses. Thus the two levels of analysis are not only measuring different conceptual questions, they are also statistically independent of each other (Rubin, Schrauf et al., 2003). Nonetheless, the between and within analyses are remarkably consistent. There is, however, one major difference in the within- and between-subject multiple regressions, which are consistent with our earlier work (Rubin, Schrauf et al., 2003). The $r$-squared values are similar for most of the equations, but are much lower for the between-subject regression of the belief variables. Thus, we can predict recollection and belief quite well within subjects and recollection but not belief between subjects. Individual differences in belief are just not predicted as well by individual differences in the cognitive measures tested here. This left more of the reliable variance in the between measures of belief for the NEO facets to explain, which is one possible reason why the NEO facets accounted for more variance for the belief than the recollection measures.

In both the between and within analyses, the recollection variables tend to have different predictor variables from the belief variables. First, although the see and setting variables are highly correlated, see enters into all predictions of the recollection variables, whereas setting does only once; by contrast, setting or spatial enter into all but one of the predictions of the belief variables, whereas see enters only for some within-subjects equations. The difference between being able to 'see in my mind' and being able to 'recall the setting where it occurred' could be a distinction between imagery and context, or between visual imagery and multi-modal spatial imagery. Second, emotions enters into all regression equations for the recollection variables, but enters into only two regression equations for the within-subjects analyses for the belief variables. Third, older memories are believed less, but not relived less. This effect is not consistently present in earlier analyses with fewer subjects and less power (Rubin, Schrauf et al., 2003). Finally it should be noted that, as in our previous work (Rubin, Schrauf et al., 2003), remember/know is more similar to measures of belief than to measures of recollection, even though it was formulated as a measure of recollection.

We have assumed that two scales, reliving and back in time, form a cluster that measures aspects of recollection, and that four scales, real/imagine, accurate, testify, and persuade, form a cluster that measures aspects of belief. We can measure this directly in the within subject analysis. The average correlation of the two measures of recollection (using Fisher's $\mathrm{z}$ to transform the correlations before averaging) is 0.66 . The average of the six correlations among the four measures of belief is 0.66 . The average of the eight correlations between each of the two questions measuring recollection and the four questions measuring belief is 0.56 . If we subtract the average of the eight between cluster correlations from the average of the seven within cluster correlations, the mean is greater than zero $(t(110)=6.91, p<0.0001)$. Thus, there is more similarity within our measures of recollection and belief than there is between them. A similar analysis shows that 
remember/know is more highly correlated to the questions measuring belief than to the questions measuring recollection $(r=0.66$ versus $r=0.57, t(109)=4.82, p<0.0001)$. Using the same technique we can check the claims noted from the multiple regressions in the previous paragraph, which depend on partial correlations among all the variables included, to ensure that they are also supported by analyses done on the simple withinsubject correlations that use only the variables in the correlations. The average correlation of see with the measures of recollection is higher than the average correlation of setting with measures of recollection ( $r=0.60$ versus $r=0.48, t(112)=7.18, p<0.0001)$, but there is only a marginal difference for measures of belief $(r=0.53$ versus $r=0.51$, $t(107)=1.92, p=0.06)$. Emotions correlates more highly with measures of recollection than belief $(r=0.62$ versus $r=0.50, t(110)=4.88, p<0.0001)$ but the opposite is true for age of memory ( $r=-0.45$ versus $r=-0.50, t(109)=2.38, p<0.05)$.

The analyses up to now have been as a cognitive psychologist interested in autobiographical memory might do them. But the NEO is a personality test and the usual way to present NEO results are as a series of scores on the five factors and 30 facets. We do this here in Table 5 for the $10 \%$ of the subjects (i.e. 12 of the 118 subjects) who scored highest and the $10 \%$ of the subjects lowest on our composite measure of recollection and separately for our composite measure of belief, as well as for the remaining $80 \%$ of the subjects in the middle ranges for all the domains and facets for which there was a difference of 10 or more on the $T$-scores of the NEO. That is, we present all domains and facets for which the high and low groups differed by one standard deviation on the reference population test norms either on the belief or recollection measure. Thus the differences would be of practical importance if they were for individuals. Except for listing the means of the subjects in the middle $80 \%$ in Table 5, the analyses are only for those subjects who are at the top and bottom $10 \%$ of the distribution on belief and recollection. In this way we ask how the personalities of subjects who are at the extremes of tending to recollect or not recollect their memories, and who are at the extremes of tending to believe or do not believe their memories, differ. Thus, even with less power

Table 5. NEO scores for the $10 \%$ of subjects scoring at extremes of composite measures for those domains and facets with a $T$-score difference of 10 or greater

\begin{tabular}{|c|c|c|c|c|c|c|c|c|}
\hline \multirow[t]{3}{*}{ Scales } & \multicolumn{4}{|c|}{ Belief } & \multicolumn{4}{|c|}{ Recollection } \\
\hline & Low & Mid & High & High & Low & Mid & High & High \\
\hline & $10 \%$ & $80 \%$ & $10 \%$ & -Low & $10 \%$ & $80 \%$ & $10 \%$ & -Low \\
\hline Mean AMQ & 4.1 & 5.3 & 6.5 & & 3.4 & 4.8 & 6.4 & \\
\hline A & 50.7 & 52.6 & 58.5 & 7.8 & 47.2 & 52.9 & 60.1 & 12.9 \\
\hline $\mathrm{C}$ & 47.7 & 50.4 & 58.6 & 10.9 & 54.1 & 50.1 & 54.1 & 0.0 \\
\hline $\mathrm{O}$ & 45.3 & 56.1 & 55.3 & 10.0 & 49.6 & 55.1 & 58.9 & 9.3 \\
\hline A3 & 50.1 & 54.1 & 60.3 & 10.2 & 47.8 & 54.3 & 61.3 & 13.5 \\
\hline A4 & 54.5 & 52.6 & 57.0 & 2.5 & 47.7 & 53.2 & 59.1 & 11.4 \\
\hline $\mathrm{C} 1$ & 44.5 & 51.3 & 56.6 & 12.1 & 54.1 & 50.3 & 54.5 & 0.4 \\
\hline $\mathrm{C} 2$ & 46.9 & 50.5 & 56.9 & 10.0 & 54.3 & 50.2 & 51.8 & -2.5 \\
\hline $\mathrm{C} 5$ & 45.4 & 48.2 & 57.1 & 11.7 & 51.3 & 48.2 & 51.2 & -0.1 \\
\hline E1 & 48.2 & 52.0 & 55.9 & 7.2 & 45.7 & 52.2 & 56.7 & 11.0 \\
\hline E4 & 42.1 & 51.4 & 53.2 & 11.1 & 47.0 & 50.6 & 54.0 & 7.0 \\
\hline E6 & 48.5 & 52.5 & 57.7 & 9.2 & 46.1 & 52.4 & 61.4 & 15.3 \\
\hline O3 & 45.2 & 54.6 & 57.2 & 12.0 & 50.8 & 53.3 & 62.1 & 11.3 \\
\hline
\end{tabular}

Note: All $14 T$-score differences that are 10 or greater are significant at the 0.05 level by an $F$ test. 
caused by having fewer subjects, we should expect more significant differences because only people who score at the extremes are included. It turns out that with 12 subjects in the high and in the low groups, an $F(1,22)$ is always significant at the 0.05 or higher if there is a 10 point difference. In general, $T$-scores of 45-55 are considered average, those below 35 and higher than 65 are considered high and low, and those below 25 or above 75 are considered extreme.

The five facets that had significant correlations (at the 0.001 level) in Table 3 had 10 point differences here with either belief or recollection, as did four other facets: A4Compliance, $\mathrm{C} 1$ - Competence, $\mathrm{C} 2$ - Order, and $\mathrm{C} 5$ - Self-discipline. It is interesting to note that there is almost no difference in recollection for $\mathrm{C}, \mathrm{C} 1, \mathrm{C} 2$, and $\mathrm{C} 5$; subjects who are at the top as opposed to bottom $10 \%$ of belief in their memories are more conscientious, but subjects who are at the top $10 \%$ of recollection of in their memories are not. People at the top $10 \%$ compared to the bottom $10 \%$ of recollecting their memories tend to be more agreeable, altruistic, and open to feelings. People at the top $10 \%$ compared to the bottom $10 \%$ of believing their memories tend to report being more competent, organized, and self-disciplined and have a generally positive outlook. Whether the differences in ratings of belief reflect a difference in accuracy is an open question.

\section{SUMMARY AND CONCLUSIONS}

The findings from our study can be divided into those that we hypothesized or expected from earlier work and those that came from the exploratory nature of the study. First, replicating our earlier findings, we found that individual differences in belief were predicted more poorly than recollection. Second, also replicating our earlier findings, we found that remember/know judgments of autobiographical memories were more similar to measures of belief than to measures of recollection. Third, based on our earlier work with the BDI we predicted and found that E6-Positive Emotions correlated with the real/imagine measure of belief, as did several other facets relating to positive emotions. This finding did not extend as clearly to other measures that we formulated to broaden our concept of belief in the accuracy of memories. Fourth, based on studies of emotional suppression, we predicted and found that $\mathrm{O} 3$ correlated with measures of recollection and belief, but not with measures of neuroticism (i.e. the $\mathrm{N}$ domain and the $\mathrm{N} 1$ to N6 facets). Thus, earlier work in the field was replicated, adding to our confidence in the results.

The study also uncovered several novel results. We had 20 measures of the properties of autobiographical memories from the AMQ and five domains and 30 facets of personality from the NEO. The pattern of results that emerged could have been extremely complex and difficult to interpret, but instead it was surprisingly simple. Of the five NEO domains, only two domains, E and O, had significant correlations with the AMQ at the 0.001, and of the 30 facets only five did: A3, E1, E4, E6, and O3. These five facets can all be seen as relating to positive emotions or openness to emotions. Similarly, our AMQ properties that measured recollection and belief and component processes of autobiographical memory had significant correlations with the NEO, whereas those measuring reported properties of the event or memories did not. An examination of the distribution of correlations shows this is not just an arbitrary cut of a power test but summarizes an underlying pattern of relations. Thus, only certain aspects of personality and certain classes of properties of autobiographical memory had measurable effects on each other. Of all the domains and 
facets of the NEO, O3 shows by far the most and strongest relations to the AMQ variables and of all the AMQ variables real/imagine shows by far the most and strongest relations to the NEO variables. Thus, these are the aspects of autobiographical memory and personality that should be examined more closely in future studies integrating memory and personality variables. On the other hand, knowing that Agreeableness, Conscientiousness, and Neuroticism have little effect on properties of autobiographical memory is as important as knowing that Extroversion and Openness to Experience do.

The results were also remarkably simple in that over several different kinds of analyses at two different levels of analysis (i.e. between and within subjects) the same basic pattern emerged. In simple correlations and a PCA done at the between subjects level, in comparisons of correlations done within subjects, and in multiple regressions done at both levels, the following results were evident. The variables intended to measure recollection and the variables intended to measure belief each clustered and were different from each other. Remember/know, as in earlier work, was more similar to measures of belief than recollection, though it is used extensively as a measure of recollection in the laboratory literature. See and emotion were more related to measures of recollection, whereas setting was more related to measures of belief.

Finally we examined the personality profile of the average subject who scored at the extremes of our composite belief and recollection measures and found them to differ on many NEO facets by more than a standard deviation in the normative distribution of the NEO. Thus, people who tend to be at the extremes of believing the accuracy of or recollecting there memories as a group appear to have different and identifiable personalities.

\section{ACKNOWLEDGEMENTS}

David C. Rubin is in the Department of Psychological and Brain Sciences, Duke University, Durham, NC 27708-0086. His research is supported by National Institute of Mental Health grant number R01 MH066079. Ilene C. Siegler is in the Department of Psychiatry and Behavioural Sciences at Duke University School of Medicine and Department of Psychology: Social and Health Sciences at Duke University. Her research is supported by Grant R01 HL55356 from the National Heart Lung and Blood Institute and the National Institute on Aging.

\section{REFERENCES}

Baddeley, A. D. (1992). What is autobiographical memory? In M. A. Conway, D. C. Rubin, H. Spinnler, \& W. A. Wagenaar (Eds.), Theoretical perspectives on autobiographical memory (pp. 13-29). Dordrecht, The Netherlands: Kluwer Academic Publishers.

Beck, A. T., Ward, C. H., Mendelson, M., Mock, J., \& Erbaugh, J. (1961). An inventory for measuring depression. Archives of General Psychiatry, 4, 561-571.

Bernstein, E. M., \& Putnam, F. W. (1986). Development, reliability and validity of a dissociation scale. Journal of Nervous and Mental Disease, 174, 727-734.

Brewer, W. F. (1996). What is recollective memory? In D. C. Rubin (Ed.), Remembering our past: Studies in autobiographical memory (pp. 19-66). Cambridge UK: Cambridge University Press.

Carlson, E. B., \& Putnam, F. W. (1993). An update on the Dissociative Experiences Scale. Dissociation, 6, 16-27. 
Cohen, S., Mermelstein, R., Kamarck, T., Hoberman, H. (1985). Measuring the functional components of social support: theory, research and application (pp. 73-94). In I. Sarason, \& B. Sarason (Eds.), Social support: Theory, research and application. The Hague: Martinus, Nijhoff.

Costa, P. T. Jr., \& McCrae, R. R. (1992). Revised NEO Personality Inventory (NEO-PIR) and the NEO Five-Factor Inventory (NEO-FFI) Professional Manual. Odessa FL: Psychological Assessment Resources.

Digman, J. M. (1990). Personality structure: emergence of the Five Factor Model. Annual Review of Psychology, 41, 417-440.

Ericsson, K. A., \& Simon, H. A. (1993). Protocol analysis: Verbal reports as data (Rev. ed.), Cambridge, MA: MIT (Bradford Books).

Estes, W. K. (1956). The problem of inference from curves based on group data. Psychological Bulletin, 53, 134-140.

Farah, M. J., Hammond, K. M., Levine, D. N., \& Calvanio, R. (1988). Visual and spatial mental imagery: dissociable systems of representation. Cognitive Psychology, 20, 439-462.

Greenberg, D. L., \& Rubin, D. C. (2003). The neuropsychology of autobiographical memory. Cortex, 39, 687-728.

John, O. P., \& Srivastava, S. (1999). The Big Five Trait Taxonomy: history, measurement and theoretical perspectives (pp. 102-138). In L. A. Pervin, \& O. P. John (Eds.), Handbook of Personality (2nd ed.). NY: Guilford Press.

Johnson, M. K., Foley, M. A., Suengas, A. G., \& Raye, C. L. (1988). Phenomenal characteristics of memories for perceived and imagined autobio-graphical events. Journal of Experimental Psychology: General, 117, 371-376.

Larsen, S. F. (1998). What is it like to remember? On phenomenal qualities of memory. In C. P. Thompson, D. J. Herrmann, D. Bruce, J. D. Reed, D. G. Payne, \& M. P. Toglia (Eds.), Autobiographical memory: Theoretical and applied perspectives (pp. 163-190). Mahwah, NJ: Erlbaum.

McCrae, R. R., \& Costa, P. T. (1999). A Five Factor Theory of Personality (pp. 139-153). In L. A. Pervin, \& O. P. John (Eds.), Handbook of Personality (2nd ed.). NY: Guilford Press.

Read, D. J., \& Winograd, E. (1998). Introduction. Applied Cognitive Psychology, 12, S1-S4.

Richards, J. M., \& Gross, J. J. (2000). Emotion regulation and memory: the cognitive costs of keeping one's cool. Journal of Personality and Social Psychology, 79, 410-424.

Rubin, D. C. (1995a). Memory in oral traditions: The cognitive psychology of epic, ballads, and counting-out rhymes. New York: Oxford University Press.

Rubin, D. C. (1995b). Stories about stories. In R. S. Wyer, Jr. (Ed.), Knowledge and memory: The real story (pp. 153-164). Hillsdale, NJ: Erlbaum.

Rubin, D. C. (1998). Beginnings of a theory of autobiographical remembering. In C. P. Thompson, D. J. Herrmann, D. Bruce, J. D. Reed, D. G. Payne, \& M. P. Toglia (Eds.), Autobiographical memory: Theoretical and applied perspectives (pp. 47-67). Mahwah, NJ: Erlbaum.

Rubin, D. C. (2002). Autobiographical memory across the lifespan. In P. Graf, \& N. Ohta (Eds.), Lifespan Development of Human Memory (pp. 159-184). Cambridge, MA: MIT Press.

Rubin, D. C., \& Greenberg, D. L. (1998). Visual memory-deficit amnesia: a distinct amnesic presentation and etiology. Proceedings of the National Academy of Sciences, 95, 5413-5416.

Rubin, D. C., Burt, C. D. B., \& Fifield, S. J. (2003). An experimental manipulation of the phenomenology of memory. Memory \& Cognition, 31, 877-886.

Rubin, D. C., Feldman, M. E., \& Beckham, J. C. (2003). Reliving, Emotions, and Fragmentation in the Autobiographical Memories of Veterans Diagnosed with PTSD. Applied Cognitive Psychology, 18, 17-35.

Rubin, D. C., Schrauf, R. W., \& Greenberg, D. L. (2003). Belief and recollection of autobiographical memories. Memory \& Cognition, 31, 887-901.

Schrauf, R. W., \& Rubin, D. C. (1998). Bilingual Autobiographical memory in older adult immigrants: a test of cognitive explanations of the reminiscence bump and the linguistic encoding of memories. Journal of Memory and Language, 39, 437-457.

Schrauf, R. W., \& Rubin, D. C. (2000). Identification of internal languages of retrieval: the bilingual encoding of memories for the personal past. Memory \& Cognition, 28, 616-623.

Siegler, I. C., \& Brummett, B. H. (2000). Associations between NEO Personality Inventory Assessment and Well-Being at Mid-life: facet level analysis. Psychology and Aging, 15, 710-714. 
Siegler, I. C., Costa, P. T., Brummett, B. H., Helms, M. J., Barefoot, J. C., Williams, R. B., Dahlstrom, W. G., Kaplan, B. H., Vitaliano, P. P., Nichaman, M. Z., Day, R. S., \& Rimer, B. K. (2003). Patterns of change in hostility from college to midlife in UNC Alumni Heart Study predict high risk status. Psychosomatic Medicine, 65, 738-745.

Tulving, E. (1983). Elements of episodic memory. Oxford: Oxford University Press.

Tulving, E. (1985). Memory and consciousness. Canadian Psychology, 25, 1-12.

Wheeler, M. A., Stuss, D. T., \& Tulving, E. (1997). Toward a theory of episodic memory: the frontal lobes and autonoetic consciousness. Psychological Bulletin, 121, 331-354.

Williams, J. M. G. (1996). Depression and the specificity of autobiographical memory. In D. C. Rubin (Ed.), Remembering our past: Studies in autobiographical memory (pp. 244-267). Cambridge: Cambridge University Press.

\section{APPENDIX: THE AUTOBIOGRAPHICAL MEMORY QUESTIONNAIRE}

The words underlined in the Appendix were underlined and set in bold in the booklet to ensure that the high end of the scale would be noted. For questions 1 through 6 and 14 the scales ranged from 1 (not at all), to 3 (vaguely), to 5 (distinctly), to 7 (as clearly as if it were happening right now). For questions 8 through 12 and 15, the scales ranged from 1 (not at all), to 3 (vaguely), to 5 (distinctly), to 7 (as much as any memory). Questions 7, 13, and 16 through 19 had unique scales, which follow each of these questions.

1. As I remember the event, I feel as though I am reliving the original event.

2. As I remember the event, I can hear it in my mind.

3. As I remember the event, I can see it in my mind.

4. As I remember the event, I or other people are talking.

5. As I remember the event, I can feel now the emotions that I felt then.

6. As I remember the event, I can recall the setting where it occurred.

7. To what extent is your memory of the event distorted by your beliefs, motives, and expectations rather than an accurate reflection of the event as a neutral observer would report it. (Scale: $1=100 \%$ distorted; $7=100 \%$ accurate).

8. Sometimes people know something happened to them without being able to actually remember it. As I think about the event, I can actually remember it rather than just knowing that it happened.

9. As I remember the event, it comes to me in words.

10. Would you be confident enough in your memory of the event to testify in a court of law.

11. As I remember the event, I feel that I travel back to the time when it happened, that I am a participant in it again, rather than an outside observer tied to the present.

12. As I remember the event, it comes to me in words or in pictures as a coherent story or episode and not as an isolated fact, observation, or scene.

13. If another witness to the event, who you generally trusted, existed and told you a very different account of the event to what extent could you be persuaded that your memory was wrong. (Scale: $1=$ not at all; $3=$ in some details; $5=$ in some main points; $7=$ completely; reverse scored as 8 -value given.)

14. As I remember the event, I know its spatial layout.

15. This memory is significant for my life because it imparts an important message for me or represents an anchor, critical juncture, or a turning point.

16. Since it happened, I have thought or talked about this event. (Scale: $1=$ not at all; $7=$ as often as any event in my life) 
17. I believe the event in my memory really occurred in the way I remember it and that I have not imagined or fabricated anything that did not occur. (Scale: $1=100 \%$ imaginary; $7=100 \%$ real)

18. To the best of your knowledge, is the memory of an event that occurred once at one particular time and place, a summary or merging of many similar or related events, or a for events that occurred over a fairly continuous extended period of time lasting more than a day. (Scale: $1=$ once; $2=$ merging; $3=$ extended)

Responses to this question were recoded to produce two scales. Once/many had a value of 1 if the subject judged the memory to take place within a single day and 0 if it took longer. Merged/extended had a value of 0 if the event lasted longer than a day and was extended in a fairly continuous manner over a period of time and 1 if it was the merging of many discrete events.

19. Please date the memory (month/day/year) as accurately as you can. Please fill in a month, day, and year even if you must estimate. If the memory extended over a period of time, report the approximate middle of the period. (scored as retention interval in days). 